\title{
FRENZIED REPRESENTATION AND THE FORBIDDEN IMAGE: 9/11'S FALLING MAN AND THE UNREPRESENTABLE
}

\author{
Kate Birdsall, \\ Michigan State University, United States.
}

\begin{abstract}
This article deconstructs the events surrounding the initial deletion of Richard Drew's "Falling Man" photograph from the archive of September 11. Via such philosophers as Paul Ricoeur and Georges Didi-Huberman, it explores the ethical implications of examining the photograph, both by itself and in montage, and investigates American views of death and dying in that context. The testimonies and images that followed the collapse of the World Trade Center brought to the fore several prescient, though often ignored, philosophical questions which surround the nature of the image, its role in shaping the narrative of an event, and whether an image of a man in the last seconds of his life, directly following his decision to die but preceding his death, functions as a reminder that we might carefully interrogate what it means to deem something unimaginable, unfathomable, unrepresentable.
\end{abstract}

Keywords: Cultural studies; American studies; philosophy; aesthetics 


\section{Introduction}

Given the nature of twenty-four hour news channels, the internet, newspapers, magazines, and written narratives, we all became witnesses to an event that many deemed too horrific for certain types of representation, despite the fact that we, collectively and as a society, watched it happen. On September 11,2001, even far away from the epicenter of what reporters began calling "an attack on America," we, the media-consuming public, were overtaken by an almost immediate desire for details. The media, in an attempt to make sense of the event, presented viewers with a seemingly endless barrage of images, sound clips, and photographs to show us what happened, and our focusing question quickly shifted: who was responsible, and why? When the towers collapsed, this became even more relevant. Everything stopped. Air travel halted, schools closed. Temporality lost its linear shape as we watched the endless loop of airplanes crashing and buildings collapsing. Even when the shock passed, we demanded answers to the "who?" and the "why?" Given the attachment to media coverage of the event, the television-watching public became obsessed with retribution.

Americans do not want to discuss death as a fundamental aspect of life, particularly when scores of us die within minutes or hours of one another on American soil. On September 11, questions surrounding death and dying became unpleasantly present in the collective American consciousness. A seemingly endless narrative about what happens when we die, particularly when traditional funerary rituals cannot take place due to the mutilation or disappearance of bodies, confronted, confused, and repelled us. Journalists, photographers, and eyewitnesses went to great lengths to preserve what they saw and heard that morning, largely due to the American public's demand for up-to-the-minute archiving, and the public responded with consternation: the direct attack on our fear of mortality, the destruction of the World Trade Center, and the testimonies and images that followed, brought to the fore several prescient, though often ignored, philosophical questions that I will investigate here. These questions surround the nature of the image, its role in shaping the narrative of an event, and whether an image of a man in the last seconds of his life, directly following his decision to die but preceding his death, functions as a reminder that we might carefully interrogate what it means to deem something unimaginable, unfathomable, unrepresentable. Even within the media circus that 9/11 became, one kind of image quickly became taboo: though we demanded photographic evidence of what occurred and planted ourselves in front of our televisions to watch the loop of footage that is now emblazoned in our brains, we were offended--even viscerally repulsed--when the media fed us photographs and video of people jumping from the towers in the moments before their collapse. 


\section{Part 1: The Photograph}

The photograph first appeared in newspapers on September 12, 2001. It was different, somehow, from other depictions of the event: the subject is a single human, clad in black and white, seemingly suspended in midair against a metallic gray, black, and white series of vertical lines. The male figure occupies only the upper third of the frame and is perfectly aligned with the background. Spanning across the horizontal axis of the image, from upper-left to lower-right, is a series of four lines in the background, on a downward diagonal, that appear to be a reflection. The angle of the figure's left leg runs parallel to these lines, forcing the eye across, down, and back to the human shape. The organic shape of the human figure exists in stark contrast to the geometric shapes behind him, and the hard lines set him apart. Running vertically along the left side of the frame are black stripes; on the right, the stripes are gray, and a fine mist hovers in the middleground. The clearest part of the man is the silhouette of his black shoe, which stands out from the stark white-and-gray background. His hands are behind his back and appear to be folded. The only part of the frame that is a color other than black, white, gray, or silver is the man's face, which is a shade of light brown, and what appears to be an orange undershirt under his white coat. He could be floating, hanging. He could be attached to an invisible cable. He could be superimposed onto the background, which, though we know is the World Trade Center, could be any office building, a striped set, or a reflection. The photograph could be a piece of art.

Without context, the image is almost soothing. It is, aesthetically speaking, beautiful. There are no signs of airplanes, of burning buildings, or of the tumult on the streets of New York. Indeed, the image is still and quiet in a way that paradoxically underscores the enormity of the event: here is a man jumping from a height of 106 stories (approximately 1300 feet), reaching a speed of 150 miles an hour before hitting the ground some ten seconds after the jump. This is not what the photograph depicts. Though it implies movement, both of the figure and of the viewer's eye, it is almost static in its quietude, and from some distance the eye might not even register that the figure is human. Richard Drew's photograph tells only one part of the story behind the most televised event in history, the event that produced the shock and awe which foreshadowed the Bush administration's later bombing campaign in Iraq and which led to scores of art exhibits, books, websites, academic journals and anthologies, and a host of conspiracy theories.

Drew's image was met with controversy from the beginning. Newspaper editors describe the horror with which they met the photograph; the editor of the Allentown, Pennsylvania Morning Call, a traditional medium-sized newspaper, recounts 
a long meeting with his editorial staff, during which some members got up and left, too sickened by the image to even consider publishing it (Singer). Hundreds of newspapers ran it anyway, and the public's response was swift, effective, and indicative of the American desire--even need--to dismiss the photograph from collective memory. Journalist Tom Junod describes one potential reason for this: "[T]he sight of the jumpers provided the corrective to those who insisted on saying what they were witnessing was 'like a movie, for this was an ending as unimaginable as it was unbearable" (1).We had to avert our gaze; we never adjusted to Falling Man in quite the same way that we accepted the footage of the airplanes hitting the towers.

Drew's photograph disappeared from view almost as quickly as it arrived, following a vehement public outcry against it. Direct testimony about the violent feelings that Falling Man evoked falls onto a continuum of interrogatory outrage: one witness' subjective "I couldn't process the information" follows others' empathetic "[it was] an impossible decision" and attempts to understand "the absolute horror of making that choice." All of these were eclipsed by a more common judgment, one that reflects the visceral feelings that the photograph produced: "I felt like I was punched in the stomach [when I saw the photograph]. It feels obscene" (all qtd. in Singer). People wrote letters and made phone calls in protest of the picture, claiming (in ways that echo arguments against photographs from Auschwitz) that looking at it and other images of the jumpers was ethically wrong and morally corrupt. The media's subsequent treatment of these photographic representations, as Marc Redfield explains in "Virtual Trauma: the Idiom of 9/11," illustrates the power of the jumpers on the American psyche: "[They became] a locus of fascination and of moralizing language about the importance of bearing witness. . . Where there is censorship there is desire. The jumpers were at the epicenter of a wider economy of ambivalence, within which frenzied representational activity coexisted with official and unofficial acts of negation" (70, emphasis mine).This unearths a paradox: the public, craving all of the information the media could provide, demanded images like "Falling Man," but were simultaneously so deeply disturbed that they deemed such images unfit for public consumption. What the images depicted was unrepresentable. And significantly, though American demand has provoked the media to evolve into a culture of frenzied representation, the kind of intimacy present in a photograph like Falling Man arouses outrage. We want to see only what we can immediately understand, not something that forces us into an extended ethical and aesthetical deliberation about viewing the final seconds of a man's life.

Junod's September, 2003 Esquire story about the falling man became another part of the 9/11 archive, largely because of its stunning characterization of media-addicted, yet moralistic, viewers: Junod describes "a nation of voyeurs" who harbor "a desire 
to face the most disturbing aspects of our most disturbing day," but simultaneously demand the deletion of the photograph from the archive. Other critics have called viewing the photograph an act of "voyeurism, as though the jumpers' experience, instead of being central to the horror, was tangential to it, a slideshow best forgotten" (3).In this way, the photograph represents the intricate relationship between viewers and the media: our collective conscious demands photographic evidence, but only if it doesn't disturb us too much. We asked and newspapers responded by printing the photograph, after which the editors were met with a critique harsh enough to provoke self-censorship--nearly every image of the jumpers disappeared, and were swiftly substituted with images of firefighters and police, heroically braving the dust and flame to save survivors. The media replaced the jumpers with the heroes, seemingly because many Americans wanted to see themselves differently: we/they craved a reflection of American fortitude and strength, not one of terror and of having to act in an unrepresentable way, seemingly based upon pure instinct.

Richard Drew responded to attacks against him--"you can't photograph this!"--and the ensuing hysteria by writing a brief article for the Los Angeles Times, in which he connects this saga to Americans' fear of confronting mortality: "What unsettles people about the picture [is that] we look at it and we put ourselves in the jumper's place. And we ask, 'Which option would I choose? Would I wait and pray for help as the flames licked at me, or jump through fresh air and sunlight, to certain death?" (3). Drew goes on to describe the manner in which editors explained their self-censorship to him, recounting a conversation in which an editor said "Americans don't want to look at pictures of death and dying over their morning cornflakes" (qtd. in Drew 2). Drew responds to this by making a direct connection to the other: "I think they're fine with it, as long as the victims aren't American" (2). I take this one step further: they're fine with it as long as the victims aren't American and aren't committing a culturally taboo act that, in all of its horror, forces Americans to contemplate whether or not they would do the same thing given the same circumstances. In Drew's words, "he is you and me" (3). This reveals another paradox: if "he is you and me," alterity forecloses the possibility of empathy. In this case, it might be that we have absorbed the falling man and assumed his burden for ourselves.

\section{Part 2: Representing the Unrepresentable and the Question of Interpretation}

All of this raises significant ethical questions about the nature of photography that one might compare to the discourse that Georges Didi-Huberman unravels in his 2008 Images in Spite of All: Four Photographs from Auschwitz and that simultaneously echo Paul Ricoeur's historiographical process as outlined in Memory, History, Forgetting. In the latter, Ricoeur explores the essence of the unrepresentable, 
describing it as "something in the event itself so monstrous as to put to flight all the modes available to representation" (256). His investigation of "the principle of a distinction between interpretation and fact," and assertion that the distinction itself is "undetermined, and the boundary between 'true' and 'false, 'imaginary' and 'factual,' 'figurative' and 'literal' story falls" illuminates the ethical questions surrounding Falling Man: the fact is that people jumped from the towers in a final act of desperation, and that many others would likely do the same thing, despite their unwillingness to contemplate the act (256). Interpretations, however, are more complicated; in this case, they range from outright denial ("they didn't really jump" or "they were blown out of the building in an explosion") to the focus on heroism that the media offered as a replacement for the troublesome images. In the case of "Falling Man," the media replaced the facts of the event with the figurative "American hero" as a way to mend our fractured collective psychology and to craft an archive with which we are more comfortable. Ricoeur's assertion that "it is an illusion to believe that factual statements can satisfy the idea of the unrepresentable, as though facts could through the virtue of their literal presentation be dissociated from their representation in the form of events in a history" is, therefore, accurate. The public could not accept any interpretation of a fact that they could also not accept (257). Though the jumpers were American citizens, they became the other, albeit a paradoxical other, following their tragic final action. Facts and interpretation are intimately linked in the formation of any archive, and any attempt to alter the archive by eliminating photographs like Falling Man and replace them with heroic images illustrates the significance of interpretation within the scope of historiography.

Aesthetics and ethics, then, become nearly inseparable. When we are confronted with a disturbing image, particularly when taken out of context, we may make an initial aesthetical judgment (Falling Man is a beautiful image), but that judgment is quickly replaced with the question of whether or not we should look at the photograph--an ethical judgment. The relationship to the photographic object becomes a juxtaposition between an event and a way of classifying and understanding that event. Didi-Huberman's insistence that the archive can--and does--reveal significant ideologies behind the marriage of aesthetics and ethics corresponds to Ricoeur's assertion that, to reach the possibility of total reflection and absolute knowledge, one must imagine--and even retrace--historical time. In this case, one might argue that replaying the footage of the airplanes hitting the World Trade Center retraces one aspect of historical time; I would add that, in order to reflect on the event in an ethical manner, we must include images of the jumpers, despite their disturbing nature. We must see the images in order to imagine the horror of $9 / 11$ which, in turn, "contradict[s] the dogma of the unimaginable" (Didi-Huberman 64), thereby revealing significant aspects of an event 
that we would rather forget. Didi-Huberman explains this: "When images disappear, words and feelings also disappear. So, too, does transmission itself" (84).

Two of Didi-Huberman's harshest critics, Gérard Wajcman and Elizabeth Pagnoux, argue that looking at photographs of this kind is fundamentally problematic, given their status as what Wajcman classifies as "beyond imagination" (qtd. in Didi-Huberman 27). For Wajcman, the photographs from Auschwitz are an attempt to represent the unimaginable in a way that runs the "risk of overinterpretation," resulting in "reassuring falsehood" that poses significant ethical and political dangers by "assimilating everything" (51-53). Pagnoux's arguments against interpreting the photographs stems from her fear of turning an analysis into a "reconstitution, fiction, creation ... [a] relentless determination to destroy the gaze" (54). The problem that Wajcman and Pagnoux have with the four photographs from Auschwitz is indeed one of interpretation and not of fact, which echoes the primary criticism of Falling Man. You can't take photographs of that because capturing the image of a man in his final moments of life is, in Wajcman's words, "unimaginable." You shouldn't interpret this photograph of the jumper because any interpretation, in Pagnoux's words, will "nullify memory" (54). It is as if interpretation were outright impossible. Indeed, "unimaginable" is also a word that surfaced in response to Drew's photograph.

Didi-Huberman's reply to Wajcman and Pagnoux, that "unimaginable' is a tragic word," and that failing to include the photographs in a montage "dissociates history from concept" (101, 103, original emphasis) becomes relevant to this investigation for a number of reasons. Firstly, there exists a significant question about the American media's replacement of images of the jumpers with images of heroes, seemingly in an attempt to sanitize the event and make it less disturbing (if such a thing is possible). Secondly, the Falling Man narrative illuminates Didi-Huberman's insistence that by asking too much or too little of an image, we develop a "fragmentary ... relation to the truth to which they bear witness" that leads to inadequacy, in the case of asking too much, or a removal from "their phenomonology, from their specificity, and from their very substance," in the case of asking too little (32-33). The solution, then, might be to consider the photograph not as the all-image of $9 / 11$, but as one aspect of a horrific event. By including Falling Man and images like it in a photographic montage of that day, the archive can go beyond "the pure and simple 'reflection' of the event. .. [or] pure and simple 'evidence" as a way to "reintroduce the historical singularities into the theoretical thinking of the phenomenon" (101, 103, original emphasis).

Even in an age when, as Didi-Huberman phrases it, the terrible has become a commodity, the images force us to remember--lest we forget, and thereby, following Ricoeur, forgive--the event in all of its parts, including the distressing reality of the 
jumpers. Far from functioning to reinforce the fetishistic voyeurism that Wajcman and Pagnoux fear, allowing the photograph into the montage reflects Didi-Huberman's argument that forming a connection between image and truth is just as important as the one between seeing and knowing. In other words, images unearth aspects of the factual truth that might lead to the ability to interpret them in a way that functions to foster a better understanding of history. The fundamental problem at the root of this controversy is that looking at Falling Man in montage is not easy. In fact, when put into context, alongside photographs of firefighters, burning buildings, explosions, and the faces of human horror on the street, it becomes an example of an image functioning "to show what we cannot see," to "visually transcend the trivial contrasts between the visible and the invisible" (133, original emphasis)--it becomes an abjection. We cannot "see death," nor can we see how someone might make the choice to jump from the World Trade Center. We cannot "see what the witnesses experienced," but including the forbidden image in the archive "gives the visual experience a power that our visible certainties or habits have the effect of pacifying, or veiling" (136, original emphasis). We must look in order to understand. Didi-Huberman's contention that photographic testimonies form a vital part of the archive that historians have an ethical obligation to include, if taken as logically sound, forecloses the possibility of continuing to eliminate Falling Man from the archive of 9/11.

For Didi-Huberman, calling a horrific event "unimaginable" and insisting that disturbing images fetishize the event become a form of unforgivable dishonesty. Indeed, one might take this to its logical extreme and decide that not considering the images is far worse than including them in the archive. Didi-Huberman's use of a Ricoeurean tactic--recognizing that it is an impossible task to think about the world without the microhistories that such photographs illustrate--effectively deconstructs Wajcman's argument that looking is fundamentally unjust, Pagnoux's contention that looking encourages us to fetishize the image, and by extension, the declaration presented by critics of Falling Man that we should not allow ourselves to see this aspect of the event. There are no facts in the archive; it is all interpretation. Even if the photographs elicit "real horror[, which is] a source of impotence for us," including them can be a source of action, not impotence. By confronting horrific images that disturb us to the core, we may employ our judgment to "situate the ethical question itself. ... Is it as a fellow human [en tant que semblable] that one human being becomes the executioner of another [?]" (154, original emphasis). Is it as fellow humans that we might stop to ponder the horrible decision to jump or not, thus forcing us to contemplate the question of mortality that we so wish to avoid? Is it as fellow humans that we might allow Falling Man into the archive, in order to recognize our alterity and uncover the truth of the event? 
If the photographs, a form of witness testimony, are "a possible point of contact . . . between the image and the real " (75, original emphasis), this underscores his later point that they are "neither nothing nor all" (111).Indeed, no narrative is neither nothing nor all. Every narrative is a point of contact, and our human desire to seek cohesive narratives that represent universal ideas may enable us to form a version of the truth that branches beyond mere intersubjectivity and into a realm where, by taking a dialectical approach, we begin to imagine visually and linguistically. We need the images (or photographic testimony) alongside the written and oral testimonies in order to responsibly build an archive. The philosophical question thus changes: what do we protect when, like Wajcman, we question the validity of an image, or of any testimony? Is calling something "unimaginable" a mere "simple refusal to think the image," or is it symptomatic of a more sinister underlying ideology (158)? My response is, on the surface, simple: in order to be ethical, we have to look at the images in order to establish connections between aesthetics, ethics, and history. The imagination itself can be an ethical and political faculty: when we view Falling Man, we recognize a human being who is similar to us, which reinscribes the horror that the event produced. Contemplating having to make that choice is difficult but necessary. Far from "unimaginable," the image reminds us that, in Didi-Huberman's words, "in the fact of every image we have to choose whether, or how, to make it participate in our knowledge and action" (180).

Ricoeur's definition of history as the transference of memory to a narrative of the "presence of absence or absence of a previous presence" (Ricoeur 22) connects to Didi-Huberman's insistence that we should use the images--even if they are neither nothing nor all--to ask questions. Ricoeur asserts that historical writing functions to represent the past, thereby creating a historical text that represents the events stored in our archives, and which have been questioned in terms of "why?" and "because." This reflects the debate between Wajcman and Didi-Huberman: "why these images, when they're not the all-image?" might be answered, in this case, with a simple "any act of the image is snatched from the impossible description of a reality" (Didi-Huberman 125).In this respect, the question here is not as transparent as a Ricoeurean witness saying "I was there. If you don't believe me, ask someone else," because of the public outcry against the photographs. It becomes more about compiling witness testimony alongside images like these. If we read the photographs as narrative, and then read the narrative surrounding the photographs, we uncover a hidden ideology that we, with Didi-Huberman, might wish to question. The question becomes one of ethical-responsibility-through-interpretation, and whether we are willing to aesthetically and ethically interpret such disturbing images.Indeed, they are not "unimaginable." On the contrary. Falling Man and images like it contain the traces of the past from which we may build archives and history. 


\section{Part 3: Grief, Derrida's Impossible Possibility, and the "Not Yet" of Death}

One aspect of this photograph that is difficult to ignore is the fact that it does not depict a dead man. It shows the act of death, the final moments of a man's life. Due to his infinite suspension in midair, the man illustrates aspects of what Derrida, in his 2002 Acts of Religion, calls "hostipitality," or an act of mourning that doubles as hospitality, and what Judith Butler characterizes as "grievability," or a way of marking lives that can be lost, lives that matter. Derrida's description of hospitality as a temporal category, or of "the question of waiting, of the time of waiting and of waiting beyond time" (Derrida 359) works to illuminate his earlier ruminations about the "not yet" of death in ways that directly apply to an image of a man who has not yet died. The photograph intrudes upon our conception of hospitality-to-the-other, since our absorption of the falling man requires an alterity that forecloses the possibility of empathy. And, though we cannot offer hospitality to the falling man or indeed to any other, it functions as a way of "welcoming the other that does not warn me of his coming" (381). When it does occur, it marks a paradoxical version of alterity: "I am like [comme] the other, there where I cannot be, and could never be like him, in his resemblance, his identification, or in his place" (390). Though we can grieve the life of the other, even that grief collapses as we absorb aspects of that life. This absorption makes the man constantly grievable; our identification with the other, in this case, means that we grieve our own future deaths as we watch him fall. This philosophical aporia challenges Richard Drew's contention that the empathetic response to the photograph might be the source of any argument against it: even though he is not me, he could be me and I could be him. By the time we view the image, the man is already dead and, despite surface differences, he will have died in the same way that, once we are gone, we all will have died.

Within American culture there exists an aversion to questioning and confronting mortality, particularly suicide; in fact, the subject is almost taboo, and we frequently relegate serious discussions of it to quiet whispers among close friends and family. We cannot prove that the World Trade Center jumpers made any kind of conscious decision to jump; in fact, the evidence indicates that, in many cases, jumping was an act of desperation, not premeditation. One thing is certain, however: when we were confronted with the pictures of jumpers, the rhetoric that followed included the notion that, somehow, they were other, particularly in relation to the heroes who stepped in to savelives. In her 2006 Precarious Life: The Powers of Mourning and Violence, Butler makes an assertion about the nature of other-in-death that, though based in her reading of Levinas, elucidates aspects of Derrida's conception of hospitality to the other: [M]y own foreignness to myself is, paradoxically, the source of my ethical connection with others. I am not fully known to myself, because part of what I am is the enigmatic traces of others. In this sense, I cannot know myself perfectly or know my 'difference' from others in an ir- 
reducible way. ... I am wounded, and I find that the wound itself testifies to the fact that I am impressionable, given over to the Other in ways that I cannot fully predict or control. (46)

We did not want to imagine ourselves as enigmatic traces of people who jumped out of buildings; we resist that kind of horrible alterity. Any kind of connection that we may have had to people who had to make such a terrible decision reminds us that we are like they were: we are human, and we may have made the same choice under similar circumstances. The "testimony of the wound" that Butler describes functions as a reminder of this, and the fact remains that we may not have been able to predict or control our behavior in response to the photograph. Even though Drew may have made an ethical decision when he shot the frames and the editors certainly made one when they ran the photograph in newspapers, we could not know that part of ourselves because, to use Derrida's phrasing, such knowledge is "incalculable."

For Derrida, the incalculable is anything that escapes rational structures. It is a moment that cannot be communicated, which leads us into an attempt to communicate that incommunicability. In this case, so many people were so shocked and offended by the image that even the possibility of expressing incommunicability became impossible: it escaped our collective grasp. In Aporias, Derrida demands that we accept the incalculable as a possibility, and his description of "the very concept of culture [as] . . synonymous with the culture of death" highlights the importance of resisting the urge to bury the image (43). The media's self-censorship thus becomes intricately woven with questions surrounding borders and limits. In the case of Falling Man, Derrida's paradoxical formulation lives: Richard Drew communicated that which was incommunicable, leading to the foreclosure of any possibility of an ethical or aesthetical consideration of the image. The choice to jump is more incalculable than the image itself for a moralistic society that refuses to empathize with other human beings who were confronted with an impossible choice. The idea of suicide, even under incalculable duress, pushes the limits of what we choose to contemplate. Making the jumpers other illustrates our collective need to maintain a safe distance between ourselves and anyone who jumped. Though they are not me, I am like they are. I may contain a part of them that inextricably alters me. And this might make me uncomfortable, irritated, less likely to be hospitable. In Butler's words, "to kill the other is to deny my life" (Butler xxvi).Within this image, then, alterity, hospitality, and mourning converge into grief for the falling man--and for ourselves. This, too, is incalculable.

In Aporias, Derrida, following Heidegger, divides the conception of death into three levels. The singular level involves a death that is always individual. No one can die for another person; each person must die his or her own death, and one's death is 


\section{K. Birdsall}

exclusively his or her own. In the case of Falling Man, many seemed content to consider death from this perspective alone. The universal level, however, involves the securing of a priority of questioning death in an existential sense, before biology, theology, physics, or anthropology, and this is where we broke down in our consideration of the image. The particular level encompasses questions of culture and history and becomes connected to the singular in this way: because our culture is so adverse to any such existential questions, we were satisfied to relegate the image to an example of the singular level, foregoing any interrogation of the culture and history from which the jumpers came. The "not yet" precedes the incalculable in this way: for Derrida, the possibility of death ("I can die") and the impossibility of death ("I cannot die") represent the possibility of death's impossibility, and mark an inaccessibility of death as such. The photograph forced us to consider the possibility of our own deaths in similar circumstances; we only know about the possibility of death at all because of our experiences with others' deaths, which reveals another paradox. The possibility of death exists even without an adequate system of representation, and even when a representation, like Falling Man, is inadequate. The "not yet" always comes too soon or too late, and part of the problem that the public had with Drew's photograph may be that it depicts the "not yet" in such stunning fashion. The suddenness of the appearance of the man's image in our minds constitutes a temporal moment that violates the idea of the incalculable: it makes visible a moment that we do not wish to see, opens wounds that we would prefer to keep hidden, and illustrates that the "stages of grief" with which we are all familiar break down when confronted with such a haunting violation of our resistance to alterity.

\section{Closure: An Ethical Decision}

Americans remember, vividly and often disturbingly, where we were when it happened. Over the course of this investigation, I tried to explain the nature of my research to various people. I was met with "I remember exactly where I was when it happened" followed by a narrative, some hesitant, some longer than others, of witness testimony. "My aunt was there."

"I was in Brooklyn and felt the ground vibrate."

"I was on my way to work and heard it on the radio."

"I was watching the Today show and it came on."

"I thought it was a joke until I saw the footage."

"It was like one of those apocalypse movies."

I remember where I was, too: I was on my way to work and heard it on the radio. I was listening to a popular morning talk show at the time, and immediately thought the host was making a most inappropriate joke, and I recall thinking that he had finally gone overboard. When I arrived at work, I pulled out the television, turned on 
the one station that the antenna would receive, and became completely immersed in the instant replay. My first reaction, that it must be a joke, was met with the slow realization that it was really happening. My response was not an uncommon one. Tom Junod writes that "[w]e have somehow taken it upon ourselves to deem [the jumpers'] deaths unworthy of witness--because we have somehow deemed the act of witness, in this one regard, unworthy of us" (Junod 5), which underscores Didi-Huberman's contention that taking photographs can be an ethical and political act. Didi-Huberman argues that photography is a performative act that cannot be separated from the documentary core of an event. Though there is something in Falling Man that we might wish to call "unrepresentable"; that is, the decision to jump, the desperate act of jumping, what it must feel like to free-fall for over 1300 feet, and the inevitable landing, the empathy that it could evoke in viewers, were it not for alterity, should not be overlooked. Indeed, the empathy/alterity division might be the problem; forcing people to ask themselves what they would do in such a situation makes the event present in a way that other kinds of images cannot. At the time, this was unfathomable--and in fact, the American media decided to replace the "disturbing" images of the jumpers with heroic pictures of firefighters and police officers, risking their lives to save survivors in the midst of chaos. The jumpers became the other: they were not me and not heroic, in spite of the fact that they became a part of me and of my recollection of the event. Collective consciousness demanded that we make some images taboo in order to encourage the "correct" ethical judgment--that 9/11 was too horrible for words or certain kinds of images--thereby eliminating any possibility of an objective ethical judgment about jumping, about photographing the jumpers, and about the need to include the photograph in the montage of $9 / 11$. 


\section{References}

Butler, Judith. 2000. Antigone’s Claim: Kinship Between Life and Death. New York: Columbia UP. Print.

--- 2010. Frames of War: When is Life Grievable? New York: Verso. Print.

--- 2006. Precarious Life: The Powers of Mourning and Violence. New York: Verso. Print

Derrida, Jacques. 1993. Aporias. Trans. Thomas Dutoit. Stanford: Stanford UP. Print

--- 2002. "Hostipitality." Acts of Religion. Ed. Gil Anidjar. New York: Routledge. Print.

Didi-Huberman, Georges. 2008. Images in Spite of All: Four Photographs from Auschwitz. Trans.

Shane B. Lillis. Chicago: U of Chicago P. Print.

Doran, Robert. 2008. Terrorism and Cultural Theory: The Singularity of 9/11. SubStance \#115, 37(1), pp. 3-19.

Drew, Richard. 2001. Falling Man. Photograph. Esquire.

--- 2003. The Horror of 9/11 That's All Too Familiar. The Los Angeles Times Online Edition.10 September 2003.

Dupuy, Jean-Pierre. 2008. Anatomy of 9/11: Evil, Rationalism, and the Sacred. SubStance \#115, 37(1), pp. 33-51.

Huk, Peter. 2005 Monological Discourse and the Creation of Villains: a staging of witnesses after 9/11. Third World Quarterly 26(3), pp. 543-550

Huyssen, Andreas. 2002. Twin Memories: Afterimages of Nine/Eleven. Grey Room 7, pp. 8-13. Junod, Tom. 2003. The Falling Man. Esquire. 8 September 2003.

Kant, Immanuel. 2007. Critique of Judgement. Trans. James Creed Meredith. Oxford World's Classics, New York.(Originally published 1793)

Kirshenblatt-Gimblett, Barbara. 2003. Kodak Moments, Flashbulb Memories: Reflections on 9/11. TDR (1988-) 47(1), pp. 11-48.

Kristeva, Julia. 1982. Powers of Horror: An Essay on Abjection. Trans. Leon S. Roudiez. Columbia University Press, New York.

Kroes, Rob. 2009. Indecent Exposure: Picturing the Horror of 9/11. New Debates in American Studies: American Multiculturalism after 9/11.Amsterdam University Press, Amsterdam, pp, 67-79. Kübler-Ross, Elizabeth. 1969. On Death and Dying. Routledge, New York.

Lyotard, Jean-François. 1992. The Inhuman--Trans. Geoffrey Bennington and Rachel Bowlby. Stanford University Press, Stanford.

Mills, Nicolaus. 2009. Images of Terror: Enduring the Scars of 9/11. Dissent 56(4), pp. 75-80.

Morrione, Deems D. 2006. When Signifiers Collide: Doubling, Semiotic Black Holes, and the Destructive Reminder of the American Un/Real. Cultural Critique 63, pp. 157-173.

Rancière, Jacques. 2009. The Emancipated Spectator. Trans. Gregory Elliott. Verso, New York, pp. 83-106.

--- 2007. The Future of the Image--Trans. Gregory Elliott. Verso, New York, pp. 109-138.

Redfield, Marc. 2007. Virtual Trauma: The Idiom of 9/11. Diacritics 37(1), pp. 55-80.

Ricoeur, Paul. 2004. Memory, History, Forgetting--Trans. Kathleen Blamey and David Pellauer. University of Chicago Press, Chicago.

9/11: The Falling Man. 2006. Dir. Henry Singer, 4oD Documentaries, 2006.

Spivak, Gayatri Chakravoty. 2004. Terror: A Speech after 9-11

1 My definition of “we," for purposes of this argument, is limited to those like myself, who, in the days immediately following the events of $9 / 11$, were riveted by the media coverage of the event. Since so many members of the American--and, indeed, global--public relied on the media for upto-the-minute coverage of the attack's aftermath, I have adopted the pronoun "we" to signify those 
of us who maintained an eye on the mediascape following the tragedy. Politically speaking, the media in fact created the kind of climate that allowed for the deletion of Falling Man; though the image was not reproduced frequently following its initial run in several hundred newspapers, it is clear that few have forgotten it.

2 The intrusion upon the linearity of temporality reflects Lyotard's idea, outlined in The Inhuman, of negative presentation; that is, the media footage of the event may have indicated the fact that, in fact, the event could not be presented. Though we attempted to grasp the largeness of $9 / 11$, we could not. Indeed, for Lyotard, any assertion of the unrepresentable becomes a temporal category. 3 Even within the large body of peer-reviewed academic work on 9/11 that exists, Falling Man is conspicuously under-represented. For an extended reflection on digital photography merging with events themselves and photography following 9/11, see Barbara Kirshenblatt-Gimblett's 2003 "Kodak Moments, Flashbulb Memories: Reflections on 9/11."Many of the academic explorations of 9/11 have been, as one might imagine, deeply political: see Andreas Huyssen's 2002 “Twin Memories: Afterimages of Nine/Eleven" for a compelling exploration of the political meanings behind the commemorations, Robert Doran's 2008 “Terrorism and Cultural Theory: The Singularity of 9/11" for an analysis of the need for a holistic interpretation of the event and direct connections between the attacks and American aversion to Islam, or Gayatri Chakravoty Spivak's 2004 "Terror: A Speech after 9-11," which focuses on Kant's "enlightened scholar" and potential humanities-based approaches to the event.

Rob Kroes (2009) treats Falling Man among other images. He focuses on the connection between Drew's photograph and Don DeLillo's 2007 novel of the same name, and asserts that "there may come a time when Drew's picture will be seen and remembered in its full iconic power, finding its place in the continued quest for the meaning of 9/11" (p. 77).

4 In Critique of Judgement, Immanuel Kant (1793/2007) describes the faculty of thinking the particular as contained under the universal and the disinterested pleasure that precedes any judgment of the beautiful $(\$ 1-5)$. He goes on to describe claims to universality that such judgments assume (\$6-9).This becomes relevant to this argument because aesthetic judgments can be neither cognitive nor based in use value; judging the photograph to be aesthetically beautiful is therefore impossible when it is taken within its context; however, it may be judged as beautiful when it stands alone.

5 Julia Kristeva (1982) might label this an instance of collective abjection. Because the man will ultimately die, we might consider Kristeva's characterization of the corpse: "[It] is the utmost of abjection. It is death infecting life. It is something rejected from which one does not part, from which one does not protect oneself as from an object. ... It beckons to us and ends up engulfing us" (p. 4).See Powers of Horror: An Essay on Abjection.

6 Junod's article identifies the source of the media's self-imposed censorship of the image as being connected to "the story behind [the photograph] ... and the search for the man pictured in it [as] our most intimate connection to the horror of that day" (p. 1). Following the reception of the photograph, Junod became admittedly obsessed with finding the man whom Drew had captured on film, as if identifying the unrepresentable with a name, an occupation, and a life story would soothe the apoplectic American psyche.

7 For a compelling analysis of the kinds of empathy evoked by Falling Man and other pictures of the jumpers, see Nicolaus Mills (2009). Mills posits that "the key to the newspapers' pictorial coverage of 9/11 was the ability of their photographers to capture scenes of individual suffering and heroism that allowed the big picture to become an intimate one" (p. 76), and goes on to explore the debate about how to classify the people who jumped; the New York coroner's office refused to rule their deaths suicide. Mills also explores some possibilities about what it means to replace horrifying 
photographs with more straightforward "stor[ies] behind ... flag-raising" (p. 79).

Redfield (2007) makes a connection to Judith Butler's statements about intersubjectivity, writing that if we affirm that part of our own individual identities stem from the "enigmatic traces of others," it makes absolute sense that we do not want to look at the pictures, since we're confronted with a trace of someone who made a decision that we might make (p. 62).

$8 \mathrm{I}$ am not comparing the events of $9 / 11$ with the events of the Shoah, but merely using Didi-Huberman's text as a way of investigating the debates between aesthetics and ethics that occurred in both situations.

9 One photograph that grew to represent 9/11 is Thomas Franklin's Three Firefighters, which depicts three New York firefighters raising an American flag, which they had captured from a yacht, in the ash and rubble of the World Trade Center. The photograph immediately appeared almost everywhere, including on the front pages of newspapers and the cover of Time magazine, and Franklin became a celebrity and a Pulitzer Prize finalist. The iconic image came to signify American strength and fortitude in the wake of tragedy: Newsweek ran it on its cover with the title "God Bless America" in its special report on 9/11 and returned to the firefighters a year later in another special issue. In 2002, the photograph became a United States postage stamp with the title "Heroes USA."

10 There exist several pieces by Derrida on the nature of hospitality. Here, I am making reference to "Hostipitality," a chapter in his 2002 Acts of Religion.

11 Junod, in his exploration of the identity of the man, uncovers some jumpers' underlying health problems (like asthma) that may have provoked them to seek fresh air and caused them to jump or to fall.

12 This is also reminiscent of Derrida's future anterior construction. In the case of "Falling Man," the future anterior reveals its significance: from here, we have to say "he will have died," not "he is dead" or "he is dying." We want to put the image, and possibly the signified itself, under erasure in order to avoid this unimaginable construction.

13 Indeed, part of the ongoing debate about the jumpers has been completely (and paradoxically) ethical: under what conditions is suicide acceptable? In a largely Judeo-Christian American society, it is unacceptable to many in most cases, even when one is faced with the alternative of burning to death.

14 In The Future of the Image, Jacques Rancière (2007) explores the unrepresentable as being "[that] which is the central category of the ethical turn in aesthetic reflection [and] is also a category that produces an indistinction between right and fact, occupying the same place in aesthetic reflection that terror does on the political plane. The idea of the unrepresentable in fact conflates two distinct notions: impossibility and interdiction" (p. 124).

In The Emancipated Spectator, Rancière (2009) makes a significant point that, although outside of the scope of this argument, deserves further consideration: viewing images of this kind makes the spectator guilty (p. 88). He goes on to argue that an image is much more than a duplicate of reality, and unearths a disturbing aspect of witnessing: "The true witness is one who does not want to witness.... The force of the silence that translates the unrepresntability of the event exists only through its representation" (pp. 91-92).

The stages of grief to which I refer here were popularized by Elizabeth Kübler-Ross who, in her 1969 On Death and Dying, characterized grief as moving in a linear fashion through, respectively, denial, anger, bargaining, depression, and acceptance. My argument here, following Derrida and Butler, is that this is impossible in a situation that invokes constant, never-ending grief.

15 Jean-Pierre Dupuy's 2008 “Anatomy of 9/11: Evil, Rationalism, and the Sacred” focuses largely on the linguistic problems with terms like " $9 / 11$ " and "Ground Zero" but also represents the body 
of academic work on 9/11--despite its formal tone and compelling analysis, Dupuy's article also includes a lengthy first-person narrative about his own experiences during the aftermath of the event. 16 Deems D. Morrione (2006) explores writing itself as a kind of violence against an event (after Derrida). In addition, Morrione makes an interesting connection to the idea of the other as I have presented it here, writing that "what was actually destroyed on September 11, 2001 [was] the ability of America to serve as the symbolic center of global politics for itself and the other" (p. 159, original emphasis). The loss of this symbolic center may partially explain the American need to replace the photographs with hero-narratives and images; this connects to the ideas put forth by Judith Butler $(2000,2010)$ in Antigone's Claim and in Frames of War: When is Life Grievable?. 